\title{
Literatúra
}

NOVOSÁD, F. (2017): Odkaz z Marburgu. (Novokantovstvo od kritiky poznania $k$ antroplógii). Bratislava: IRIS.

PADGETT, A. G. (2002): Dialectical realism in Theology and Science. In:

Perspectives on Science and Christian Faith. Vol. 54., No. 3, 184 - 192.

doc. PhDr. Vladimír Manda, CSc.

Katedra filozofie

Filozofická fakulta

Univerzita Konštantína Filozofa v Nitre

Hodžova 1

94974 Nitra

vmanda@ukf.sk

\section{Joerg Rasche - Thomas Singer (eds.): Europe's Many Souls. Exploring Cultural Complexes and Identities}

New Orleans: Spring Journal Books, 2016, p. 435.

This outstandingly written and perfectly timed book is an extremely helpful and essential for understanding Europe. Present-day issues one can observe on European continent have, of course, their deep and profound roots in particular cultural complexes, deep historical, political and cultural conditioning. The endeavour of today's Europeans to achieve peace in diversity is a task during which they must be aware of complex historico-psychological conditioning of European continent.

But this volume is not the first project attempting to chart up to now unchartered waters of so-called cultural complex. Spring Journal Books publisher has already ventured on the territory of Latin America, Australia, USA, Switzerland or Australia. ${ }^{1}$ Obliged to C. G. Jung very modest incursions on the territory of social sciences and politics in Jung's Wotan (1936) and his After the Catastrophe (1945) Singer and Kimbles have recognized Jung's theory of complexes as the basic tool for their concept of cultural complex already in 2004: “(...) his theory of complexes has never been systematically applied to the life of groups and to what Jung and his followers

1 (San Roque - Dowd - Tacey 2011), (Amezaga - Barcellos - Capriles - Gerson - Ramos 2012), (Schenk 2012). 
have been fond of calling "collective". Applying Jung's theory of complexes to the cultural level of the psyche and the life of group (and how the life of the group exists in the psyche of the individual) is a new addition (...)" (Singer - Kimbles 2004, 2). At the same time, their concept is not only extension of Jung's understanding of complex but constitutes its totally new application to the social, cultural and political levels of human existence without direct reference to the archetypal level of psyche. In this respect cultural complex concept assumes critical stance towards Jung's socio-psychological thought: "To understand, Jung went straight to to the archetypal level of psyche (...). (...), in his seminal 1936 essay 'Wotan', Jung warns of the primitive, Mercurial god of lightning and destruction seizing the German psyche. But, by leaving the social, economic, and political level of German psychological experience out of his analysis in 'Wotan', Jung opened himself up to profound misunderstanding and misinterpretation" (Singer - Kimbles 2004, 2 - 3). Exposed to $20^{\text {th }}$ century European crises and its numerous unhuman atrocities, Jung was very aware of the collective shadow and consequently "a substantial part of Jung's genius was his sensitivity to the perils of the individual's falling into the grips of collective life (...)" (Singer - Kimbles 2004, 4). Determining weak point of Jung's thought as "natural introversion (and his appeal to other introverts)" that leads to "unknowledged tendency to set the individual up against or in opposition to the life of the group" (Singer - Kimbles 2004,4), proponents of cultural complex theory constitute another wave of critical revision of their maître's theory: "Our old Jungian theory of archetypal possessions unleashing destructive forces is good on its own terms. But it has gotten stale in its application where everything unpleasant (...) is explained away by the 'shadow' to explain every destructive force in the psyche, we stop thinking" (Rasche - Singer 2016, 5).

In the very beginning of the $21^{\text {st }}$ century Singer and Kimbles (and before them Joseph Henderson and Michael Vannoy Adams) ventured on the field they called "inner sociology" which, although archetypally programmed (within particular family and society), does not make up an individual psyche but a collective psyche: "There is something in the tension between the individual and the group that is wholesome and natural". Being aware of such a division between individual and collective "we may even begin to become aware of the positive value of living in the collective. We may also begin to bet better at differentiating cultural complexes from individual complexes" (Rasche - Singer 2016, 4).

The modus operandi of cultural complexes does not differ from those individual. They are: (1) autonomous (sometimes dormant, sometimes active and take hold of thoughts, feelings, memories, images, behaviour of the collective), (2) repetitive (their life is uninterrupted in the collective psyche for generations, centuries, millennia and when activated they behave unchanged, expressing the same emotional and ideological content over and over again), (3) they collect experiences and memories that validate their own point of view (once cultural complex is established, 
it has a capacity to make sure that whatever happens fits into its pre-existing perspective), (4) thoughts and perspective of cultural complexes tend to be simplistic and black and white, rigid, (5) have a very strong affects or emotions, (6) they are not always destructive, (7) they are not the same as national identity, national character or soul of a culture. Moreover, they are both psychopathological and normative:

\begin{abstract}
“(...) in the Australian volume, Placing Psyche, considerable attention was given to the various ways indigenous people have been treated by the non-indigenous immigrants to Australia over time. It is not a pretty picture; social attitudes toward the Aboriginal people are clearly entrenched cultural complexes that we can say are psychopathological. The same can be said of Anti-Semitism and Anti-Islamism in Europe and the West. These are expressions of deep-seated, long-standing cultural complexes (...)" (Rasche - Singer 2016, 9).
\end{abstract}

Nevertheless, in this book complex, identity and soul are interconnected. Different chapters deal with different countries and the complex is approached in differrent ways. Frequently, differentiation between them (Poland, Greece, Spain) is difficult, sometimes the complex is approached by means of poetry (England, Scotland, Ireland), works of great novelists (Russia) or poetry and literature of land (the Czech Republic). But this book does not omit the less agreeable element inherent in the national identity - cultural complex connection: the fact that complex is frequently crucial part of national identity: "it is easy to see how what is denied as part of national identity becomes the fuel for an unconscious complex of shame, guilt, and denial" (Rasche - Singer 2016, 11).

There is an introduction by Thomas Singer (Rasche - Singer 2016, 1-13) and another one by Joerg Rasche (Rasche - Singer 2016, 14-31) and three sections in the book. The first one entitled Soul, Identity, and Cultural Complexes in Individual European Countries (Rasche - Singer 2016, 37-252) covers countries like Britain, Greece, Russia, Spain, Czech Republic, Poland, Switzerland, Germany, Russia and Serbia, the second entitled Daughters of the Asian Princess - the Feminine in Europe (Rasche - Singer, 257-338) covers Denmark, Italy and Austria, and the third and last section The Greater European Family: Cultural Complexes in All European Countries (Rasche - Singer 2016, 343-435) deals with more complex issues like Christian-Jewish complex in Europeans, European animus in Israel, Child part of European cultural complex or old cultural complexes activated by today's tension between Europe and Islamic cultures.

It is noteworthy that this book frequently refers to political and social events and changes taking place in the contemporary Europe but all the chapters were written before summer 2015 and thus, as Singer emphasizes, "fractures and tensions increased since. (...) Tragic news of bombings in Paris, mass sexual assaults in Cologne, ongoing debt crisis in Greece, and growing conflict over refugees throughout 
Europe might have found their way into the papers of this volume if they were written just yesterday" (Rasche - Singer 2016, 3). Like that Singer's introduction contains ubiquitous question of European question of (dis-)unity, (re-)conciliation, division between the North and the South or the East and the West. But regardless of our historical moment, Europe permanently goes through tides of integration and disintegration. Singer's glance catches North-South polarity "growing economic Northern and Southern European countries", (Rasche - Singer 2016, 3), immigration problem or rise of anti-Islamism and reminds us times of Berlin Wall fall when post-WW II bi-polar world order got disintegrated and the long period of integration was initiated. In this context Singer reminds Michael Fordham's model: "(...) disintegration is a normal phase of development when change is essential and the wholeness of a previous moment has to be released in favor of taking in new breath, new life, new possibilities" (Rasche - Singer 2016, 3). Singer observes that all these tidal waves have to do with new mass media ("the high tide of constellated archetypes in the collective unconsciousness not only provokes the media but also can be triggered by the media", Rasche - Singer 2016, 4). But, according to him, considering only archetypal perspective (orthodox Jungian perspective) would be misleading - that is why cultural complex viewpoint requires much more complex and multidisciplinary approach: "(...) I have become increasingly aware that an exclusively archetypal perspective on events between nations can itself become dangerously misleading by generating deep, even irreparable misunderstandings" (Rasche - Singer 2016, 4).

In its beginning Joerg Rasche's introduction (Rasche - Singer 2016, 15-31) focuses on implications of ancient myth (myth of Europa), fantasy of united Europe triggered the by fall of the Eastern block, exemplification of what cultural complex means in European context, elucidation of circumambulatio as a method of approaching cultural complexes, national complexes in Europe, role of the memory in the cultural complex, and finally a question of reconciliation. At the very beginning Rasche proposes a myth of Asian princess Europa ("the one with shinging eyes") as an image and metaphor of European identity rising out of Asia which exemplifies in the story of Troy and Carthage. A deep (unconscious) link between Europe and Asia seems to be a complex issue because in Europe Asian heritage "was regarded with respect and suspicious. Already in the oldest mythology, there are traces of projections and complexes regarding Asian cultures, religions, and rituals" (Rasche - Singer 2016, 16). Historically a distinct European identity shaping started with Punic wars and carried on through Roman Empire, medieval Christian culture till $19^{\text {th }}$ century "Europe of Nations" and post-Cold War fantasy-project of European Union when "new-old national states emerged out of the ruins of the Eastern Bloc. Age-old fears, projections, and archaic patterns of self-esteem built on tribal and ethnic identities came to life again, fueled by the media and political leaders (...). Old spirits are back - evil and good ones, Specters and phantoms, spirits of ambi- 
guous cultural ancestors (...)" (Rasche - Singer 2016, 17-18). How to identify fundamental and disparate elements of this patchwork continent? This book tries to look at it through the lenses of various national cultural complexes and to do that it frequently makes use of literature, poetry, history. For example, for Rasche (a German) it is Schiller's The Robbers that points at Nazi phenomena. French-German mutual projection is an age-old issue and as Rasche says: "As a German, I find it quite difficult to talk with the French about the Vichy government, which also shows how cultural complexes exist in the space between two cultures" (Rasche - Singer 2016, 21).

Rasche emphasizes role of collective emotions in the cultural complex which is something many disciplines do not take into consideration: "Unlike the various academic approaches, the cultural complex notion centralizes the emotional dimension. The neglect of the emotional value in academic disciplines (...) can be found in the abuse of pseudoscientific theories during the twentieth century" (Rasche - Singer 2016, 24) and adds "in Germany, for example, any kind of emotional statement in a scientific publication was and still is not well accepted" (Rasche - Singer 2016, 24). But emotions play a very important role because they - being undervalued - frequently form a cumulative trauma which continually plays itself out in the outward attitudes and behaviour of peoples. And, to complicate an issue a little bit more, cultural and national complexes are mutually intertwined: "the part of the complex oriented to the outer world does not exist without the other corresponding reciprocal complex. The interrelatedness of cultural complexes means that if a cultural or national complex is to be transformed this may only be possible in relation to the transformation of the neighbor's complex" (Rasche - Singer 2016, 26). Because Europe's history is full of wars, violations, mutual killings and consequently people and cultures were traumatized. Many of these traumas are still not integrated into collective consciousness but live their life in the subconscious stratas of collective psyche. Rasche offers an apt image of crypt: "The repressed collective trauma is enclosed like a psychic dead body. You cannot speak about it, and it is passed silently and unconsciously to the next generation" (Rasche - Singer 2016, 27). That's an image that has many exemplification in European history.

It the chapter dedicated to Britain (Autonomy and Insularity in an Island Race, Rasche - Singer 2016, 37-68) Jules Cashford views Britain's cultural complex from the perspective of projection ("what is unconscious is projected, that's rule" /"projections change the world into a replica of one's unknown face",(Jung quoted in Cashford: Rasche - Singer 2016,39) which is extremely important when looking at national mythology: "the whole mythology could be taken as a projection of the collective unconscious" (Jung quoted in Cashford: Rasche - Singer 2016, 39) - it is there where Cashford looks for archetypal core of British complex. Cashford observes some crucial points in British identity: island or insularity, freedom or auto- 
nomy as key-words that open up for us British collective psyche, its positive and negative pole. Evangelos Tsempelis' chapter (The Inner Riddle of "Greek Psychic Debt") seems to be a reaction to Greek financial crisis in 2008 and he maps Greek cultural complex regarding home, roots, belonging and national identity in the context of the history of the Balcans. For Tsempelis, one of the most important symptoms of Greek cultural complex is the oscillation between manic pole and depressive pole: "(...) at any point in time Greeks seem to oscillate between one-sided euphoric aspirations of success and equally one-sided self-indulgent feelings of defeatist pessimism. On a different axis this oscillation registers its movement between two poles: one recognized by feelings of superiority associated with a welldocumented historical proclivity (...). And a second pole characterized by a sense of inferiority to the West and to Europe" (Rasche - Singer 2016, 84).

Elena Volodina's chapter deals with The Mystery of Russian Soul which has to do with eternal and ubiquitous "expectation of the miraculous. In just a bit, a miracle will happen, and our lives will change radically: we shall become healthy and rich, and we won't need to do anything for it" (Rasche - Singer 2016, 94). Such hopes are natured already in Russian fairy and folk tales or myths (folktale heroes and fools: simpleminded people acting in an absurd but miraculous way and thus saving the world). According to Volodina, "inside the Russian soul is a deep urge to encounter the numinous", longing that reflects "purely pagan desire for a miracle" (Rasche - Singer 2016, 95) which has little to do with Orthodox Christianity. For Volodina this pagan background underlies Great Russian Literature as well, i.e. it is populated by "superior and inferior pagan deities (...) forgotten Slavonic soul (...) reborn as literary soul" (Rasche - Singer 2016, 96) exemplified by "The Raskolnikov complex", "The Anna Karenina complex" or "The Oblomov complex" still living in soul of contemporary Russians.

Olivia del Castillo's chapter (The Catalan Vault) seems to anticipate 2017 events in Barcelona. It deals with transformation of personal and cultural complex in the case of Catalunya. Inspired by her own experience of extreme Spanish nationalism, Castillo writes about dehumanizing and destructive effects of the individual by the collective ideology of extreme nationalism. To her, it is a sort of intrusion or invasion that can result in dissociative disease. This is why she speaks about "psychic incest": "(...) I highlight the influence of psychic incest in the pathological dissociation that occurs both at the individual level, when consciousness is overtaken by certain unconscious complexes, as well as at the collective level, when consciousness is overtaken by extreme nationalism, which I think of as a cultural complex" (Rasche - Singer 2016, 111).

Next chapter (The Forefather Cultural Complex) about the Czech Republic is written by the Czech analyst Martin Skála. In his eyes Czech cultural complex has to do with "ever-present sense of threat" and "national consciousness and patriotism aren't strong components of the Czech cultural complex" (Rasche - Singer 2016, 
136). Similarly to Volodina, Skála differentiates various Czech cultural complexes: the Prague cultural complex, the greengrocer-dissident complex, the Kafka complex or the Meyrink complex emerging from the common mystical pagan background. But all these partial complexes have to do with "a sort of mistrust of the surrounding world, of one's own doctrines and institutions, as well as of the external world or reality overall" (Rasche - Singer 2016,154) which is usually solved by "double life we lead" (ibid.).

In her article Malgorzata Kalinowska introduces us into Polish cultural complex termed as "the suffering hero complex" and links it with Polish Messianism. In her view, cultural complex of Polish psyche emerges from a long history of cumulative trauma. Kalinowka admits that being open to future is quite difficult if one inherits such a complex, but to her it is exactly what Polish soul is about. This theme is quite visible in Polish literature. The phrase "suffering hero" does not appear in Polish literature, philosophy or historiography but it includes what is typical for Polish experience because "it contains not only Christian symbolism but also romantic paradox. It includes both faithfulness to God's plans (...) as well as a Promethean rebellion against His will" (Rasche - Singer 2016, 165). This is an attitude visible throughout all the Polish history of difficult struggles and took it form "during the times of partition (...), and has expressed itself in rituals, religious observances, and social myths" and the myth itself originated in the $19^{\text {th }}$ century romanticism. All of them are "culture carriers" that help nation's identity in difficult times. Suffering hero complex is intimately linked to Polish messianism which also helped the people of Poland "to make sense of repeated defeats and suffering" (Rasche - Singer 2016, 167).

Angela Graf-Nold's investigation of Swiss cultural complex proceeds from Count Hermann Keyserling's Das Spectrum Europas (1928) and his strict evaluation of Swiss character where there is no "das Höhere" ("the higher"), where local Bodenständigkeit (down-to-earthiness) is just the caricature of German Heimatgefüghl (sense of home). For Keyserling the Swiss "are a non-noble folk par excellence" (Rasche - Singer 2016, 200). According to Graf-Nold Keyserling's Das Spectrum Europas led its author inevitably (and unconsciously) to the study of both cultural and (unconsciously) his own complexes. According to Graf-Nold Keyserling's "association to Switzerland mirrored his own fears and wishes, especially the fear of being marginalized in a democratic society instead of being able to rely on an in-herited influential role as a noble grand seigneur" (Rasche - Singer 2016, 203). Concluding her chapter Graf-Nold emphasises a crucial finding: "free expression of unconscious thoughts and feelings are not only useless but also rather dangerous if not compensated by the meticulous work of attempting the objectification of the subjective" (Rasche - Singer 2016, 203).

Gert Sauer's chapter is dedicated to cultural complexes of Germany and Russia or of so-called complex of German superiority and the Russian complex of feeling 
encircled by hungry barbarians. Sauer address both complexes at the same time because both nations have painful and very often parallel history - both constituted its national identity at the same time. Sauer reminds us the continuing existence of both complexes in the unconscious of both nations and as a prove offers Ukrainian crisis (2013). In his view "the West showed no awareness of Russia's deeply rooted complex related to the fear of being surrounded and attacked. These mutually interactive complexes of Western superiority and the Russian fear of being surrounded have come to full flower in the ongoing des-truction of human lives in the Ukraine's civil war" (Rasche - Singer 2016, 214).

Marijana Popović and Jelena S. Matić introduce us in the liminality of Serbian capital, Belgrade, and, consequently to cultural complex of liminality in Serbian soul. Discourse of liminality entered psychology through anthropological studies of Arnold Van Gennep of rites of passage. Rites of passage Van Gennep described as serving as means of being transferred from one social status to another one. During liminal periods social hierarchies may be reversed or temporarily dissolved, continuity becomes uncertain as well as future. Belgrade became liminal city already at Roman times, but both authors interpret liminality as a crossroad and a symbol of coniunctio oppositorum as well: "Belgrade has never managed together all the opposite and conflicting sides of its history, to transcend the polarity between construction and destruction", it is "a city in constant self-renewal, forever under construction and reconstruction and deconstruction" (Rasche - Singer 2016, 250).

Limited space does not allow us thorough description of all the chapters of this ground-breaking work, but the book is surely one of the most significant contributions to cultural complex interdisciplinary studies published within last ten years. This field of study is going to broaden our perspective when retrospectively thinking about Europe's past and its possible future(s). Moreover, this book helps us to link depths of collective psyche and socio-political reality.

Aleš Vrbata

\section{References}

SAN ROQUE, C. - DOWD, A. - TACEY, D. (eds.) (2011): Placing Psyche. Exploring Cultural Complexes in Australia, New Orleans: Spring Journal Books. AMEZAGA, P. - BARCELLOS, G. - CAPRILES, Á. - GERSON, J. - RAMOS, D. (eds.) (2012): Listening to Latin America. Listening to Latin America: Exploring Cultural Complexes in Brazil, Chile, Colombia, Mexico, Uruguay, and Venezuela, New Orleans: Spring Journal Books.

SCHENK, R. (2012): American Soul, New Orleans: Spring Journal Books. SINGER, T. - KIMBLES, S. (2004): The Cultural Complex. Contemporary Jungian

Perspectives on Psyche and Society, London: Brunner Routledge. 


\section{Aleš Vrbata, PhD.}

State University of Feira de Santana

Literature and Cultural Diversity Post-Graduate Department

AVENIDA TRANSNORDESTINA S/N

Caixa Postal: $252-294$

CEP: 44.036-900

Feira de Santana

Brasil

alesvrbata@hotmail.com 